\title{
Management of Multifocal/Multicentric Breast Cancer: Current Perspective
}

\author{
Amelia Milulescu ${ }^{1,28}$, Luigi Di Marino ${ }^{38}$, Nickolas Peradze ${ }^{4}$, Antonio Toesca ${ }^{4}$ \\ 'Elias University Hospital, Bucharest Romania \\ 2Department of Obstetrics and Gynecology, Carol Davila University of Medicine and Pharmacy, Bucharest, Romania \\ ${ }^{3}$ Department of Mini-Invasive General Surgery, University of Federico II Naples, Italy \\ ${ }^{4}$ Division of Breast Surgery, European Institute of Oncology, Milan, Italy
}

Corresponding author:

Amelia Milulescu, MD

Assistant Professor

Department of Obstetrics and

Gynecology, Elias University Hospital

Carol Davila University of Medicine

and Pharmacy, Bucharest, Romania

17, Marasti street, district 1

E-mail: amelia.milulescu@gmail.com

\&authors with equal contribution.

\section{Rezumat}

Managementul cancerului de sân multicentric/multifocal. Tendințe actuale

Incidența cancerului de sân multicentric (MC) şi multifocal (MF) are rezultate diverse printre diferitele studii clinice existente în prezent, în principal, din cauza lipsei unei clasificãri şi a unei definiții standardizatea a acestor douã entitãți diferite. Tratamentul chirurgical optim pentru cancerul de sân multiplu ipsilateral, rãmâne un subiect de discuție. Chirurgia conservatoare a sânului are o contraindicatie relativã în tratamentul cancerului multifocal şi al cancerul multicentric. În acest review narativ am analizat diferențele dintre cancerul de sân MF şi cel MC, rolul rezonanței magnetice în detecția leziunilor multiple ale sânului şi în luarea deciziei tratamentului chirurgical. Am evaluat date din literatura legate de fezabilitatea chirurgiei conservatoare a sânului şi de modalitãțile de tratament loco regional. Studii recente au arãtat cã tratamentul chirurgical conservator al pacientelor cu cancer de sân MF/MC împreunã cu radioterapie şi terapie sistemicã adjuvantã pot avea rate scãzute de recidivã. Pentru a confirma aceste rezultate sunt necesare studii prospective.

Cuvinte cheie: sân, cancer, chirurgia conservatoare a sânului, mastectomie, cancer de sân multicentric, cancer de sân multifocal, mastectomie nipplesparing, reconstrucție mamarã

\section{Abstract}

The incidence of multifocal (MF) and multicentric (MC) breast cancer has a wide variation among different clinical studies, mostly due to the lack of a standardized classification and definition of these two separate entities. The optimal surgical treatment for multiple ipsilateral breast cancer remains a long debated subject. Multifocal and multicentric breast cancer is usually considered a relative contraindication for breast conserving therapy (BCT). In this narrative review we analyzed differences between MC and MF early breast cancer, the role of magnetic resonance imaging (MRI) in detection of multiple breast lesions, and its role in the surgical approach. We evaluate data from the litera- 
ture about feasibility of breast conservative surgery and loco-regional treatment modalities. Recent studies brought evidence that treatment of patients with MC/MF breast cancer with BCT plus radiotherapy and adjuvant systemic therapy can have low-rates for in-breast recurrence. Prospective studies are needed to confirm these findings.

Key words: breast, cancer, breast conservative surgery, mastectomy, multicentric breast cancer, multifocal breast cancer, nipple-sparing mastectomy, breast reconstruction

\section{Introduction}

The surgical treatment for unifocal breast cancers evolved from mastectomy to BCT based on data demonstrating equivalent survival from treatment strategies of the late 1970s to early 1980s (1). The optimal surgical management for multiple ipsilateral breast cancer (MIBC) is still long debated. In the past, first and sole approach was represented by mastectomy with axillary lymph node dissection. Multifocal and MC are still most of the time considered as having a relative contraindication for BCT. The reasons for this belief is based on two reasons: on one hand, the discerned higher risk for in-breast recurrence since it is assumed that in these type of breast cancers the risk of more invasive foci in the breast is higher, and hence radiotherapy can be less effective. Secondly, the less good cosmetic outcome due to wider excisions (2). During the last years surgeons, in according with oncologists, breast radiologists and radiotherapists, began moving on more conservative overtures. This study reviews literature and focus on different surgical management of multicentric and multifocal breast cancers, taking into account surgical and molecular progress of the last few years. Anatomic pathologic definitions, molecular characterization, conventional imaging and breast magnetic resonance (MRI), and other variables, allow more and more for a conservative approach.

\section{Methods}

We performed a narrative review of the published evidence in the literature on MIBC. Keywords used were breast, cancer, breast conservative surgery, mastectomy, multicentric breast cancer, multifocal breast cancer, nipple-sparing mastectomy, breast reconstruction. Relevance of publications was evaluated from titles at the beginning, then from abstracts. Research was carried out on the following electronic database: MEDLINE, (1970 to November 2016), ISI Current Contents databases (1980 to November 2016), and Cochrane Library database (1990 to November 2016).
Concerning inclusion criteria, studies were included if they fulfilled specific eligibility criteria. Studies should present data from multivariable analyses and reported the hazard ratio (HR) for overall survival (OS) or disease-free survival (DFS) for multifocal as compared to unifocal tumors in women with early stage breast cancer; studies were taken into consideration, if the extraction of the odds ratio (OR) for overall survival, disease free survival, disease-specific survival, and local relapse rate at 5 and/or 10 years was present. Concerning exclusion criteria, studies that failed to fulfill the inclusion criteria, or studies in which the outcomes of interest were not reported, were excluded. Other exclusion criteria included: full text not available; review article; letter to the editor; editorial report; case report; duplicate publication; abstract. Key words yielded 241 citations (Fig. 1), but 180 were excluded as they did not satisfy the selection criteria. Also, were excluded studies with less than 15 patients. From the remaining 61 articles, 24 were excluded on the basis of the full text.

\section{Differences between multifocal and multicentric breast cancer}

Until recently, the terms multicentricity and multifocality were used interchangeably in the literature

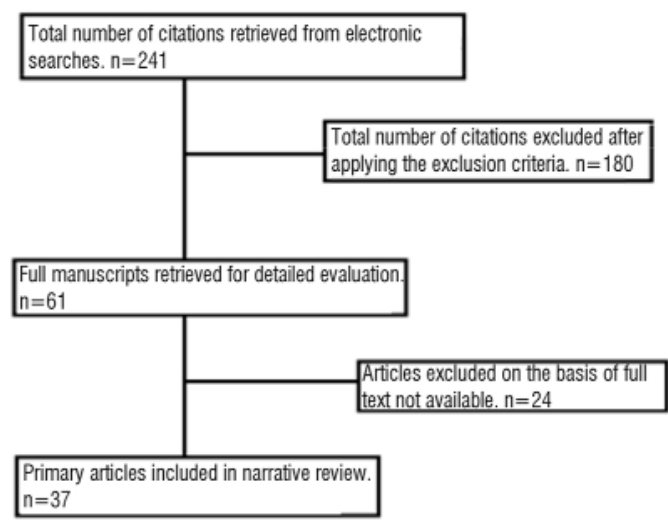

Figure 1. Study selection process for narrative review 
to describe multiple ipsilateral lesions of the breast, without applying a correct definition of these two distinct aspects. This has created confusion that further contributed to the variation in reported prevalence. Multiple tumors are defined by the presence of synchronous, distinct, invasive tumors in the same breast, and comprise $\mathrm{MC}$ and $\mathrm{MF}$ carcinomas. Only recently the literature begins making difference between multifocal and multicentric. Multicentric cancer is defined as the presence of at least two lesions in two different quadrants of the breast or in the same quadrant but at least $5 \mathrm{~cm}$ apart. Multifocal cancer si defined as the presence of several lesions in the same quadrant of the breast or in different quadrants is the distance between foci is at least $5 \mathrm{~cm}$ (3). Katz et al. describe multifocality as foci separated by less than $4 \mathrm{~cm}$ or located in the same quadrant, while multicentric as foci separated by at least $4 \mathrm{~cm}$ (4). For Vlastos et al., multicentricity is more than one site of origin for carcinoma, while multifocality indicated multiple foci of the same tumor (5). According to the latest edition of TNM, multiple ipsilateral breast cancer (MIBC) is defined as multiple, simultaneous, ipsilateral and synchronous breast cancer lesions. For $\mathrm{T}$ category in particular, tumor size is assessed by the largest tumor focus, adding suffix “(m)" to indicate multiplicity.

The use of breast cancer quadrants for classification is now recognized as inappropriate since it is based on an arbitrary definition, not considering the breast lymphatic anatomy. The rich lymphatic system of the breast originates from walls of mammary ducts an interlobular connective tissue (6). There are many connections between the deep lymphatic and superficial coetaneous lymphatic channels, especially around the nipple in subreolar plexus.

The drainage from this plexus is primarily to axillary lymph nodes, nonetheless. The continuous network of radially arranged breast ducts connecting the mammary lobules with the nipple and the blood vessel distribution makes clear the inappropriate division of breast in 4 quadrants.

Vera-Badillo et al. published in 2014 a metaanalysis of twenty-two studies, that included 67557 patients that the rate of MF/MC tumors was $9,5 \%$ (6434 patients) (7).

Many authors demonstrated a strong link between multifocality and lymph node involvement, suggesting more aggressive behavior and influencing the DFS and OS. A consistent number of studies show that women with MIBC have a higher risk of nodal involvement than women with unifocal, but no significant risk difference is found in risk compared with unifocal when is used aggregate diameter (8-10).

Rezo et al. in a prospective cohort study on a database of 812 women with ipsilateral invasive breast cancer, from which 141 had MC and MF breast cancer, measured the diameter of the largest deposit, the aggregate diameter and the aggregate volume of all foci. Tumor size was associated with progression free survival and OS in multicentric and multifocal breast cancer, using any of the three measures; however, the diameter of the largest deposit provided the best fit in (11).

\section{Imaging}

The golden standard for the diagnosis of breast cancer and also for evaluating the extent of the disease is represented by ultrasound and mammography.

Pre-operative assessment of the extent of the tumor in the management of breast cancer is vital. Magnetic resonance imaging (MRI) is currently indicated in cases of invasive lobular carcinoma on histology, a dense breast parenchymal pattern on $2 \mathrm{D}$ digital mammography (2DDM), suspicion of multifocal breast cancer and if there is a discrepancy between the clinical and radiological extent of disease. Several benefits of breast MRI are cited in the literature. The highest advantage of using MRI, it's is high sensitivity which, in 10$30 \%$ of patients, detects new foci of cancer not seen using other imaging tests (12).

Miller et. al (13) studied 81 patients undergoing pretreatment MRI. In 39 patients $(48,1 \%)$ there were new lesions identified, of these, 21 patients (54\%) multifocal disease was seen, $10(26 \%)$ had multicentric breast cancer and in 8 patients, contra lateral disease was found.

Nevertheless, the impact of breast MRI is still debated due to its false positive rates and due to a large number of benign lesions found.

If additional suspicious findings are identified, preoperative biopsies must be performed to limit the number of unnecessary wider excisions or mastectomies (14).

\section{Breast conservative surgery (BCS) vs. Mastectomy for MIBC}

Sioban et al, (15) conducted a retrospective study on a cohort of 3722 patients from which $2816(76 \%)$ had unifocal (UF) breast cancer, and 906 (24\%) patients had MIBC (MF n=673 and MC n=233). 
The 5-year local recurrence (LR) control rate, with a median follow up of 52 months, was $99 \%$ for MF, $96 \%$ for $\mathrm{MC}$ and $98 \%$ for unifocal cancer. $\mathrm{MF}$ and MC tumors were associated with more grade 3 disease, lobular differentiation, and HER2 positivity. $62,4 \%$ of UF tumors were treated with BCT, compared to $38 \%$ of MF tumors $(\mathrm{p}<0.001)$. $31.7 \%$ of UF tumors were treated with mastectomy alone compared with $48.1 \%$ of MF tumors $(p<.001)$ and $60.9 \%$ of $\mathrm{MC}$ tumors $(\mathrm{p}<.001)$. The median follow-up for all patients was 52 months, 64 patients $(1.7 \%)$ had loco regional recurrence (LRR): $49(1.7 \%)$ in the UF group, 9 (1.3\%) in the MF group and $6(2.6 \%)$ in the MC group. There was no difference in the 5-year LR control rate among the UF group (98\%), the MF group (99\%), and the MC group $(96 \%)(p=0.44)$.

Yerushalmi et al (16) published a populationbased study, between 1989 and 2005, in which were found no statistically significant differences regarding the local relapse rate between unifocal and $\mathrm{MC} / \mathrm{MF}$ groups, regardless of the surgical option chose (BCT or mastectomy).

A total of 19754 women met the inclusion criteria. The median follow-up was 7.9 years. From the total of patients, 11983 underwent BCT (UF: 11683 and MF/MC: 300) and 7771 underwent mastectomy (UF: 6884 and MF/MC: 887). The cumulative 10-year local recurrence rates among unifocal and MC/MF disease were $4.6 \%$ versus $5.5 \%$ for the BCT group $(\mathrm{p}=0.76)$ and $5.8 \%$ versus $6.5 \%$ for the mastectomy group $(\mathrm{p}=0.77)$.

In the same study by Yerushalmi et al (16), patients who benefited from BCT were aged 50 to 69 years and they had smaller tumors with-out extensive DCIS. In multivariate analysis recurrence rates were similar for $\mathrm{MC} / \mathrm{MF}$ and unifocal tumors $(\mathrm{P}=0.6)$ so the authors concluded that $\mathrm{BCT}$ is a reasonable option in selected cases of MC/MF tumors, in particular in women aged 50-69 years, with small size tumors $(<1 \mathrm{~cm})$ without extensive DCIS.

Other studies compared the surgical treatment for MF/MC cancer. Kaplan et al. (17) studied 55 patients (36 patients treated with BCS and 19 patients treated with mastectomy); the study showed no significant difference in the local $(p=0.54)$ or distant $(p=0.20)$ 5-year disease free survival between the two groups. Lim et al (18) on a retrospective study on 478 patients with MF/ MC (147 underwent BCS and 331 underwent mastectomy) and 930 patients with unifocal cancer who underwent BCS. The mean follow-up period was 59.33 months for breast conserving group and
64.98 months for mastectomy group. The 5-year overall survival was $93.38 \%$ for BCS and $94.53 \%$ for mastectomy $(p=0.208)$. The 5-year diseasefree survival was $89.08 \%$ for BCS and $91.88 \%$ for mastectomy $(\mathrm{p}=0.451)$.

Wolters et al (19), in a multicentric cohort study concluded that in the MF cancers, both BCT and mastectomy would be appropriate guideline adherent options for T1-2 tumors; for the MC cancers they concluded that the size of the tumor has an important impact on survival.

Gentilini et al (20) retrieved 476 patients who underwent conservative surgery for MIBC between March 1997 and December 2002. Median follow-up was 73 months. From the total of 476, 421 had MF cancer and 55 had MC cancer. In 88 patients (18.5\%) was diagnosed invasive lobular carcinoma, invasive mixed ductal lobular in $27(5.7 \%)$ whereas 261 patients $(55.3 \%)$ had nodal involvement. In this trial the rate of local relapse was $5.1 \%$ at 5 years, similar to recurrence rates to patients with unifocal breast cancer. Their attitude, in conclusion, is in favor of breast conservation.

Regarding the management of DCIS, some authors (21) state that the indications for mastectomy are uncertain but extensive micro calcification on the pre-operative mammogram is a risk factor for local recurrence after conservation surgery. High recurrence rates occur with larger tumours ( $>40 \mathrm{~mm}$ diameter) and mastectomy should be considered for such cases. Certainly, it should also be consided that patients undergoing breast conserving surgery should routinely have the DCIS excised with microscopically clear radial margins so, where breast tissue is to be moved at the time of surgery (eg oncoplastic techniques) particular consideration must be given to ensuring that further excision of involved margins can be easily carried out without a patient per se being committed to a mastectomy.

Concerning the fact that LCIS is associated with an increased risk of incomplete excision after $\mathrm{BCT}$, and that there are concerns about the safe use of BCT for patients with LCIS, they appear unfounded because several studies show no difference in $\mathrm{LR}$ rate between $\mathrm{BCT}$ and mastectomy (22-23). Also, a lobular histology compared to ductal histology showed no significant difference in LR rate (24). Lobular histology is not a contra indication for a successfully performed BCT.

In the meta-analysis of Vera-Badillo et al (7), the impact on survival of MF/MC tumors was compared to that of unifocal tumors from data gathered form 22 studies and 67557 patients. From 
the total of 67557 patients, $n=6565$ had MF/MC and $n=62326$ UF. MC/MF tumors were associated with decreased OS but the difference was not statistically significant in RFS $(p=0.07)$.

\section{Cosmetic result after surgical procedure}

In MC/MFD carcinomas, the localization of tumors is of utmost importance to determine the type of resection allowing both favorable cosmetic results and negative margins.

Surgeons continue to perform mastectomy in patients with MF/MC breast cancer and one of the reasons is constituted by the poor cosmetic results, due to large resections for BCS. The continuous evolution of oncological and reconstructive surgical techniques makes is possible for mastectomy to be less and less invasive (25-26).

In June 2014, the daVinci Robot was used, for the first time in breast surgery, to perform a mastectomy and immediate reconstruction (27-28). The entire procedure, the mastectomy plus reconstruction, was done in the same session, through a small incision in the underarm region. The aim of the robotic mastectomy is to obtain the highquality aesthetic result, without any visible scars. In 2016, in "The Breast", the authors published their results and conclusions of the first phase of feasibility and safety (29).

\section{Discussion}

Multifocal and multicentric breast cancer still remains a debated and challenging subject for all the physicians involved in treating these pathologies. There are several reports stating that MF and MC breast cancers are associated with lower prognostic factors, such as more frequent lymph node metastasis (19).

Many studies also found that there are associations between age and patient-related, physician related and guideline adherent treatments, that influence survival parameter (30-32). While consensus recommends the use of breast MRI in high risk patients, for staging evaluation to define extent of cancer and identify synchronous lesions (Grade 2B Recommendation by the NCCN)(33) remains controversial. Multiple studies have demonstrated changes in treatment plans based on preoperative MRI findings that range from $14 \%$ to $29 \%$. The overtreatment of breast cancer is also an argument against routine breast MRI in newly diagnosed breast cancer. Screening breast MRIs has been demonstrated to be advantageous in high-risk patients; however, the use of routine breast MRIs prior to tratment, after diagnosis of breast cancer remains controversial (34).

There are still not yet sufficient studies to demonstrate the optimal surgical treatment for $\mathrm{MF}$ and $\mathrm{MC}$ breast cancer. Hence, it is not clear that $\mathrm{BCT}$ can provide equal oncologic safety concerning survival parameters as mastectomy. Recently, there has been some evidence that BCT can provide a feasible option in MF and MC breast cancer (35), but further prospective and maybe randomized trials are needed to address the role of BCT in MF and MC.

Assumed that is impossible to define guidelines, the analysis of existing studies is difficult because literature continues to propose several articles completely different in results while having the same endpoints (36-41).

\section{Conclusion}

In conclusion, women with multifocal breast tumors appear to have adverse outcome compared to those with unifocal tumors, including higher rates of recurrence and death. However, substantial heterogeneity among studies prevents determination of a precise estimate of the increased risk and therefore there is an urgent need of further studies.

Authors' contribution: A.M: acquisition, analysis, interpretation of data for the work; drafting the work, revising it critically for important intellectual content; participated in writing or technical editing of the manuscript; L. di M.: final approval of the version to be published; agreement to be accountable for all aspects of the work in ensuring that questions related to the accuracy or integrity of any part of the work are appropriately investigated and resolved. N.P. \& A.T.: served as scientific advisors; critically reviewed the study proposal; final approval of the version to be published; agreement to be accountable for all aspects of the work in ensuring that questions related to the accuracy or integrity of any part of the work are appropriately investigated and resolved

\section{References}

1. Veronesi U, Saccozzi R, Del Vecchio M, Banfi A, Clemente C, De Lena $\mathrm{M}$, et al. Comparing radical mastectomy with quadrantectomy, axillary dissection, and radiotherapy in patients with small cancers of the breast. N Engl J Med. 1981;305(1):6-11.

2. Nijenhuis MV, Emiel J, Rutgers Th. Conservative surgery for multifocal/multicentric breast cancer. The Breast. 2015;24 Suppl 2:S96 S99. D0I: http://dx.doi.org/10.1016/j.breast.2015.07.023

3. Houvenaeghel G, Tallet A, Jalaguier-Coudray A, Cohen M, Bannier M, Jauffret-Fara $C$, et al. Is breast conservative surgery a reasonable option in multifocal or multicentric tumors? World $\mathrm{J}$ Clin Oncol. 
2016;7(2):234-42. doi: 10.5306/wjco.v7.i2.234.

4. Katz A, Strom EA, Bulchholz TA, Theriault R, Singletary SE, McNeese MD. The influence of pathologic tumor characteristics on loco regional recurrence rates following mastectomy. Int J Radiat Oncol Biol Phys. 2001;50:73542.

5. Vlastos G, Rubio IT, Mirza NQ, Newman LA, Aurora R, Alderfer J, et al. Impact of multicentricity on clinical outcomes in patients with T1-2, No-1, M0 breast cancer. Ann Surg Oncol. 2000;7(8):581-7.

6. Jesinger RA. Breast anatomy for the interventionalist. Tech Vasc Interv Radiol. 2014;17(1):3-9. doi: 10.1053/j.tvir.2013.12.002.

7. Vera-Badillo FE, Napoleone M, Ocana A, Templeton AJ, Seruga B, Al-Mubarak M, et al. Effect of multifocality and multicentricity on outcome in early stage breast cancer: a systematic review and meta-analysis. Breast Cancer Res Treat. 2014;146(2):235-44. doi: 10.1007/s10549-014-3018-3. Epub 2014 Jun 14

8. Rezo A, Rodins K, Davis A, Shadbolt B, Zhang Y, Huynh F, et al. Assessment of tumor size and its relationship to nodal involvment in multifocal and multicentric breast cancer. Presented at the American Society of Clinical Oncologists (ASCO) Annual Meeting, Chicago. J Clin Oncol 2007;25. [abstr 10602]

9. Treserra F, Rodriguez I, Garcia-Yuste M, Grases PJ, Ara C, Fabregas R. Tumor size and limph node status in multifocal breast cancer. Breast J. 2007;13(1):68-71.

10. Andea AA, Bouwman D, Wallis T, Visscher DW. Correlation of tumor volume and surface area with limph node status in patients with multifocal/multicentric breast carcinoma. Cancer. 2004;100(1):20-7.

11. Rezo A, Dahlstrom J, Shadbolt B, Rodins K, Zhang Y, Davis AJ, et al. Tumor size and survival in multicentric and multifocal breast cancer Breast. 2011;20(3):259-63. doi: 10.1016/j.breast.2011.01.005

12. Esserman L, Hylton N, Yassa L, Barclay J, Frankel S, Sickles E. Utility of magnetic resonance imaging in the management of breast cancer: evidence for improved preoperative staging. J Clin Oncol. 1999;17(1):110-9.

13. Miller S, Causey MW, Cahanding N, Brown T, Smith D (2015) Prog Science 2(2):e04 I. doi: 10.14721/pscience.2015.e04.

14. Sardanelli F, Boetes C, Borisch B, Decker T, Federico M, Gilbert FJ, et al. Magnetic resonance imaging of the breast: recommendations from the EUSOMA working group. Eur J Cancer. 2010;46(8):1296316. doi: 10.1016/j.ejca.2010.02.015.

15. Lynch SP, Lei X, Hsu L, Meric-Bernstam F, Buchholz TA, Zhang H, et al. Breast cancer multifocality and multicentricity and locoregional recurrence. Oncologist. 2013;18(11):1167-73. doi: 10.1634/theoncologist.2013-0167. Epub 2013 Oct 17.

16. Yerushalmi R, Tyldesley S, Woods R, Kennecke HF, Speers C, Gelmon KA. Is breast-conserving therapy a safe option for patients with tumor multicentricity and multifocality? Ann Oncol. 2012; 23(4):876-81. doi: 10.1093/annonc/mdr326. Epub 2011 Aug 2.

17. Kaplan J, Giron G, Tartter PI, Bleiweiss IJ, Estabrook A, Smith SR. Breast conservation in patients with multiple ipsilateral synchronous cancers. J Am Coll Surg. 2003;197(5):726-9.

18. Lim W, Park E-H, Choi S-L, Seo J-Y, Kim H-J, Chang M-A, et al. Breast conserving surgery for multifocal breast cancer. Ann Surg. 2009;249(1):87-90. doi: 10.1097/SLA.0b013e31818e41c0.

19. Wolters R, Wöckel A, Janni W, Novopashenny I, Ebner F, Kreienberg R, et al. Comparing the outcome between multicentric and multifocal breast cancer: what is the impact on survival, and is there a role for guidline-adherent adjuvant therapy? A retrospective multicenter cohort study of 8,935 patients. Breast Cancer Res Treat. 2013;142(3):579-90. doi: 10.1007/s10549-013-2772-y.

20. Gentilini O, Botteri E, Rotmensz N, Da Lima L, Caliskan M, GarciaEtienne CA, et al. Conservative surgery in patients with multifocal/ multicentric breast cancer. Breast Cancer Res Treat. 2009;113(3): 577-83. doi: 10.1007/s10549-008-9959-7.

21. Surgical guidelines for the management of breast cancer, Association of Breast Surgery at BASO 2009. EJSO. 2009;35: S1-S22. doi:10.1016/ j.ejso.2009.01.008

22. Diepenmaat $L A$, van der Sangen MJ, van de Poll-Franse $L V$, van Beek MW, van Berlo CL, Luiten EJ, et al.The impact of postmastectomy radiotherapy on local control in patients with invasive lobular breast cancer. Radiother Oncol. 2009;91(1):49-53. doi: 10.1016/j.radonc. 2008.09.012.

23. Singletary SE, Patel-Parekh L, Bland KI. Treatment trends in early- stage invasive lobular carcinoma: a report from the National Cancer Data Base. Ann Surg. 2005;242(2):281-9.

24. Jones HA, Antonini N, Hart AA, Peterse JL, Horiot JC, Collin F, et al. Impact of pathological characteristics on local relapse after breastconserving therapy: a subgroup analysis of the EORTC boost versus no boost trial. J Clin Oncol. 2009;27(30):4939-47. doi: 10.1200/JCO. 2008.21.5764.

25. Botteri E, Rotmensz N, Sangalli C, Toesca A, Peradze N, De Oliveira Filho $\mathrm{HR}$, et al. Unavoidable mastectomy for ipsilateral breast tumour recurrence after conservative surgery: patient outcome. Ann Oncol. 2009;20(6):1008e12. http://dx.doi.org/10.1093/annonc/mdn732.

26. Botteri E, Gentilini O, Rotmensz N, Veronesi P, Ratini S, Fraga-Guedes $\mathrm{C}$, et al. Mastectomy without radiotherapy: outcome analysis after 10 years of follow up in a single institution. Breast Cancer Res Treat. 2012;134(3):1221e8.http://dx.doi.org/10.1007/s10549-012-2044-2.

27. Toesca A, Peradze N, Galimberti V, Manconi A, Intra M, Gentilini 0, et al. Robotic nipple-sparing mastectomy and immediate breast reconstruction with implant: first report of surgical technique. Ann Surg. 2015 Oct 21. [Epub ahead of print]

28. Toesca A, Manconi A, Peradze N, Loschi P, Panzeri R, Granata M, et al. 1931 Preliminary report of robotic nipple-sparing mastectomy and immediate breast reconstruction with implant. Eur J Cancer September 2015;51(3):S309. DOI: 10.1016/S0959-8049(16)30880-2

29. Toesca A, Peradze N, Manconi A, Galimberti V, Intra M, Colleoni M, et al. Robotic nipple-sparing mastectomy for the treatment of breast cancer: Feasibility and safety study. Breast. 2017;31:51-56. doi: 10.1016/.j.breast.2016.10.009.

30. Hancke K, Denkinger MD, König J, Kurzeder C, Wöckel A, Herr D, et al. Standard treatment of female patients with breast cancer decreases substantially for women aged 70 years and older: a German clinical cohort study. Ann Oncol. 2010 Apr;21(4):748-53. doi: 10.1093/annonc /mdp364.

31. Janssen-Heijnen ML, Maas HA, Lemmens VE, Houterman S, Louwman WJ, Verheij CD, et al. The correlation of age and comorbidity with therapy and survival in cancer patients in North-Brabant and NorthLimburg, 1995-2001. Ned Tijdschr Geneeskd. 149(30):1686-1690 Dutch

32. DeMichele A, Putt M, Zhang Y, Glick JH, Norman S. Older age predicts a decline in adjuvant chemotherapy recommendations for patients with breast carcinoma: evidence from a tertiary care cohort of chemotherapy-eligible patients. Cancer. 2003;97(9):2150-9.

33. Bevers TB, Anderson BO, Bonaccio E, Buys S, Daly MB, Dempsey PJ, et al. NCCN clinical practice guidelines in oncology: breast cancer screening and diagnosis. J Natl Compr Canc Netw. 2009;7(10):1060-96.

34. Bleicher RJ, Ciocca RM, Egleston BL, Sesa L, Evers K, Sigurdson ER, et al. Association of routine pretreatment magnetic resonance imaging with time to surgery, mastectomy rate, and margin status. J Am Coll Surg. 2009;209(2):180-7; quiz 294-5. doi: 10.1016/j.jamcollsurg. 2009.04.010.

35. Bauman L, Barth RJ, Rosenkranz KM. Breast conservation in women with multifocal-multicentric breast cancer: is it feasible? Ann Surg Oncol. 2010;17 Suppl 3:325-9. doi: 10.1245/s10434-010-1247-1.

36. Nos C, Bourgeois D, Darles C, Asselain B, Campana F, Zafrani B, et al. Conservative treatment of multifocal breast cancer: a comparative study. Bull Cancer. 1999;86(2):184-8. French

37. Wilson LD, Beinfield M, McKhann CF, Haffty BG. Conservative surgery and radiatio in the treatment of synchronous ipsilateral breast cancer. Cancer. 1993;72(1):137-42.

38. Goldhirsch A, Glick JH, Gelber RD, Coates AS, Thürlimann B, Senn HJ, et al. Meeting highlights: international expert consensus on the primary therapy of early breast cancer 2005. Ann Oncol. 2005;16(10): 1569-83. Epub 2005 Sep 7.

39. Coombs NJ, Boyages J. Multifocal and multicentric breast cancer: does each focus matter? J Clin Oncol. 2005;23(30):7497-502.

40. Adkisson CD, Bagaria SP, Parker As, Bray JM, Gibson T, Thomas CS, et al. Whic elegible breast conservation patients choose mastectomy in the setting of newly diagnosed breast cancer? Ann Surg Oncol. 2012;19(4):1129-36. doi: 10.1245/s10434-011-2080-x.

41. Boyages J, Jayasinghe UW, Coombs N. Multifocal breast cancer and survival: each focus does matter particularly for larger tumours. Eur $\mathrm{J}$ Cancer. 2010;46(11):1990-6. doi: 10.1016/j.ejca.2010.03.003. 